\title{
New antiplatelet drugs for acute coronary syndrome
}

\section{Praveen Indraratna \\ Medical registrar ${ }^{1}$ \\ Associate lecturer ${ }^{2}$ \\ Researcher $^{3}$ \\ Christopher Cao \\ Senior cardiothoracic \\ registrar ${ }^{4}$ \\ Conjoint lecturer ${ }^{2}$ \\ Board member ${ }^{3}$ \\ 'St George Hospital \\ ${ }^{2}$ University of New South Wales \\ ${ }^{3}$ Collaborative Research (CORE) group \\ ${ }^{4}$ Prince of Wales Hospital Sydney}

\section{Key words}

aspirin, clopidogrel,

prasugrel, ticagrelor

Aust Prescr 2014;37:182-6

\section{SUMMARY \\ Ticagrelor and prasugrel are antiplatelet drugs that are alternatives to clopidogrel in acute coronary syndrome. Their advantages include reduced rates of ischaemia and stent thrombosis. \\ The risk of major bleeding is likely to be higher with prasugrel compared to clopidogrel. Intracranial haemorrhage appears to be slightly more common with ticagrelor than with clopidogrel, and it can also cause dyspnoea and ventricular pauses early in treatment. \\ When patients taking prasugrel or ticagrelor require surgery, perioperative management is challenging. The treating cardiologist should be consulted whenever treatment cessation is considered.}

\section{Introduction}

Patients presenting with acute coronary syndromes, such as myocardial infarction, are treated with dual antiplatelet therapy to prevent recurrent ischaemia and mortality. After receiving loading doses, patients may undergo either percutaneous or surgical revascularisation. Following percutaneous revascularisation, aspirin is typically continued indefinitely, and another antiplatelet drug, most commonly clopidogrel, is continued for 12 months. While aspirin is also continued indefinitely following coronary artery bypass grafting, the role of a second antiplatelet drug remains unclear, and their use has

\section{From the Editor}

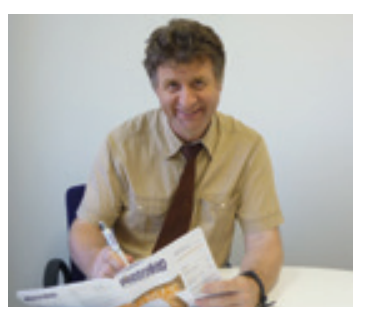

The new antiplatelet drugs help to improve the survival of patients with acute coronary syndrome. Praveen Indraratna and Christopher Cao remind us that the drugs also create problems if major surgery is needed. Austin Ng and Leonard Kritharides inform us about the other factors cardiologists consider in their preoperative assessments.

Assessing the patient is also very important when deciding whether to prescribe testosterone. Donald Perry-Keene says the hormone should not be used to manage non-specific symptoms such as reduced energy or poor concentration.

Judicious prescribing is also needed in palliative care. Debra Rowett and David Currow are concerned that adverse effects may be overlooked.

Terminal illness is likely to affect drug disposition. Bruce Charles believes that population pharmacokinetics can help us investigate drugs in patient groups that are difficult to study, including children.

While some children may be prescribed drugs such as imipramine for incontinence, Gail Nankivell and Patrina Caldwell advise that conservative treatment should be tried first. not been standardised. Data from recently published large randomised trials suggest that prasugrel and ticagrelor may be alternatives to clopidogrel in acute coronary syndrome. ${ }^{1-3}$

\section{Indications for use}

Current guidelines published by the Cardiac Society of Australia and New Zealand (CSANZ) ${ }^{4}$ recommend that either ticagrelor or prasugrel should be considered as alternative drugs to clopidogrel in patients presenting with ST-elevation myocardial infarction who are at high risk of recurrent ischaemic events, such as those with:

- diabetes mellitus

- stent thrombosis

- recurrent ischaemic events despite clopidogrel therapy

- a high burden of disease on coronary angiography.

The guidelines also recommend the use of either ticagrelor or prasugrel instead of clopidogrel in all patients with high-risk non-ST-elevation acute coronary syndromes who are judged to be of low risk for haemorrhagic events. It should be noted, however, that local hospital protocols may differ from the CSANZ guidelines.

\section{Clinical pharmacology}

In acute coronary syndrome, damage to atherosclerotic plaques exposes platelet activating factors such as tissue factor, collagen and von Willebrand factor. The platelets release granules containing adenosine diphosphate. This binds to the $\mathrm{P} 2 \mathrm{Y}_{12}$ receptor on the surface of the platelets as the first step of the platelet aggregation pathway. ${ }^{5}$ Antagonism at this receptor inhibits platelet aggregation. 
Clopidogrel and prasugrel are thienopyridines.

They bind irreversibly to the $\mathrm{P} 2 \mathrm{Y}_{12}$ receptor for the entire lifespan of the platelet (5-9 days). In contrast, ticagrelor binds reversibly, so platelet inhibition is not as prolonged and twice-daily dosing is required to achieve therapeutic concentrations. ${ }^{5}$ All three drugs require a loading dose when given in acute coronary syndrome (Table). ${ }^{6-15}$

The time to onset of maximal platelet inhibition after administration of loading doses of antiplatelet drugs is an important consideration, particularly in ST-elevation myocardial infarction, as prompt revascularisation is required. Prasugrel achieves maximal platelet inhibition in approximately 30 minutes, whereas ticagrelor takes two hours. For clopidogrel, the time to maximal platelet inhibition is dose-dependent. A $600 \mathrm{mg}$ dose achieves maximal platelet inhibition within two hours, whereas a dose of $300 \mathrm{mg}$ takes eight hours. For this reason, loading doses of $600 \mathrm{mg}$ have been used for clopidogrel in the acute management of ST-elevation myocardial infarction.

'Clopidogrel resistance' is a poorly defined phenomenon that may affect $4-30 \%$ of the population. ${ }^{7,16}$ It may be related to a genetic variation of the cytochrome P450 2C19 enzymes that does not appear to affect either prasugrel or ticagrelor.

\section{Prasugrel: safety and efficacy}

Prasugrel has been compared to clopidogrel in two separate phase III randomised trials. It has not yet been directly compared to ticagrelor in a randomised clinical trial.

The TRITON-TIMI-38 study randomised patients $(n=16843)$ undergoing percutaneous coronary intervention to either prasugrel or clopidogrel, in combination with aspirin (75 to $162 \mathrm{mg}$ daily). ${ }^{1}$ The efficacy end point (a composite of death due to cardiovascular causes, non-fatal myocardial infarction and non-fatal stroke) was reached by $12.1 \%$ of the patients randomised to clopidogrel, compared with $9.9 \%$ of the patients taking prasugrel. This significant difference $(p<0.001)$ was offset by an increase in major bleeding in the prasugrel group ( $2.4 \%$ vs $1.8 \%, p<0.001)$ which was sometimes fatal $(0.4 \%$ vs $0.1 \%, p=0.002)$. The overall mortality rates for clopidogrel and prasugrel were similar

Table Pharmacological summary of P2Y $\mathbf{1}_{12}$ inhibitors

\begin{tabular}{|c|c|c|c|}
\hline & Clopidogrel & Prasugrel & Ticagrelor \\
\hline Loading dose & $300 \mathrm{mg}$ or $600 \mathrm{mg}$ & $60 \mathrm{mg}$ & $180 \mathrm{mg}$ \\
\hline Maintenance dose & 75 mg daily & 10 mg daily & 90 mg twice daily \\
\hline $\mathrm{P} 2 \mathrm{Y}_{12}$ receptor binding & Irreversible & Irreversible & Reversible \\
\hline Hepatic metabolism & $\begin{array}{l}\text { Two-step metabolism involving CYP2C19 } \\
\text { to convert it to an active metabolite }{ }^{6} \\
\text { Dysfunction of this enzyme may be the } \\
\text { cause of clopidogrel resistance }^{7}\end{array}$ & $\begin{array}{l}\text { Rapidly hydrolysed to an } \\
\text { intermediate metabolite, and } \\
\text { then further metabolised by } \\
\text { CYP3A and CYP2B63 }\end{array}$ & Metabolised by CYP3A4 \\
\hline $\begin{array}{l}\text { Examples of drug interactions } \\
\text { affecting } \mathrm{P}_{2} \mathrm{Y}_{12} \text { inhibitors }\end{array}$ & $\begin{array}{l}\text { CYP2C19 inhibitors will decrease } \\
\text { efficacy e.g. clarithromycin, fluconazole, } \\
\text { omeprazole }\end{array}$ & $\begin{array}{l}\text { No significant CYP } \\
\text { interactions, however data } \\
\text { are limited }\end{array}$ & $\begin{array}{l}\text { CYP3A4 inhibitors will increase adverse } \\
\text { effects e.g. clarithromycin } \\
\text { CYP3A4 inducers will decrease efficacy } \\
\text { e.g. carbamazepine, dexamethasone, } \\
\text { rifampicin }\end{array}$ \\
\hline $\begin{array}{l}\text { Examples of } \mathrm{P}_{2} \mathrm{Y}_{12} \text { inhibitors } \\
\text { affecting other drugs }\end{array}$ & - & - & $\begin{array}{l}\text { Inhibits CYP3A4 so may increase } \\
\text { concentrations of substrates such as } \\
\text { simvastatin }^{*} \\
\text { Ticagrelor is also a weak P-glycoprotein } \\
\text { inhibitor }^{10} \text { so digoxin concentrations } \\
\text { increase and need monitoring }^{11}\end{array}$ \\
\hline $\begin{array}{l}\text { Time to onset of maximal } \\
\text { platelet inhibition }\end{array}$ & $\begin{array}{l}8 \text { hours }(300 \mathrm{mg})^{12} \\
2 \text { hours }(600 \mathrm{mg})^{13}\end{array}$ & 30 minutes $^{14}$ & 2 hours $^{12}$ \\
\hline $\begin{array}{l}\text { Time to recover platelet } \\
\text { function after ceasing } \\
\text { medication }\end{array}$ & 5 days $^{15}$ & 7 days $^{15}$ & $2-3$ days $^{12}$ \\
\hline
\end{tabular}

* $\quad$ simvastatin doses of 40 mg or more may be associated with an increased risk of myopathy and other adverse effects

CYP cytochrome 
(3.0\% vs 3.2\%, p=0.64). ${ }^{1}$ Subgroup analysis revealed that patients with a history of stroke or transient ischaemic attack experienced poorer outcomes with prasugrel. In patients over 75 years of age or weighing less than $60 \mathrm{~kg}$ treated with prasugrel, there was no benefit in relation to the composite end point.

The TRILOGY-ACS study included 7243 patients who did not undergo revascularisation. ${ }^{2}$ There was no difference in the combined end point in the prasugrel and clopidogrel groups ( $13.9 \%$ vs $16 \%, p=0.21$ ) and the risk of haemorrhage was similar.

Prasugrel may be of overall benefit to patients undergoing percutaneous coronary intervention, but it has a higher risk of haemorrhage. It would be better to use clopidogrel for patients with:

- a history of stroke or transient ischaemic attack

- age more than 75 years

- body weight less than $60 \mathrm{~kg}$.

\section{Ticagrelor: safety and efficacy}

The PLATO trial compared ticagrelor with clopidogrel, both in combination with aspirin, in 18624 patients with acute coronary syndrome. ${ }^{3}$ Ticagrelor significantly reduced the occurrence of the 12-month composite end point (consisting of death from cardiovascular causes, stroke and myocardial infarction) compared to clopidogrel (9.8\% vs $11.7 \%$, $\mathrm{p}<0.001)$. The dose of aspirin used in the study was 75-100 mg.

The overall incidence of major bleeding for ticagrelor and clopidogrel was similar (11.6\% vs $11.2 \%, \mathrm{p}=0.43$ ), as was the rate of fatal bleeding $(0.3 \%$ vs $0.3 \%$, $\mathrm{p}=0.66$ ). Ticagrelor, however, had a higher propensity to cause intracranial haemorrhage $(0.3 \%$ vs $0.2 \%$, $\mathrm{p}=0.06$ ). The rate of bleeding related to urgent coronary artery bypass grafting was $7.4 \%$ with ticagrelor and $7.9 \%$ with clopidogrel. ${ }^{3}$

Dyspnoea was more common with ticagrelor ( $13.8 \%$ vs $7.8 \%, p<0.001)$, however this adverse effect was not related to any drug-induced cardiac, metabolic or respiratory dysfunction. The cause of this dyspnoea remains unknown, but ticagrelor inhibits cellular uptake of endogenous adenosine, and dyspnoea is a common adverse effect of adenosine administration. ${ }^{17}$ Further studies have found the dyspnoea to be transient, ${ }^{18}$ but ticagrelor should be avoided in patients who have chronic shortness of breath, such as those with chronic lung disease or symptomatic left ventricular failure.

In the PLATO study, ventricular pauses longer than three seconds were more common in the first week of therapy with ticagrelor ( $5.8 \%$ vs $3.6 \%, p=0.01$ ), but this difference resolved after one month of treatment. Uric acid and creatinine also increased slightly in patients taking ticagrelor.

Compliance with ticagrelor has been a concern, given its twice-daily dosing requirement, and more rapid offset time. In the PLATO study, the rates of adherence between clopidogrel and ticagrelor were equal (82.8\% in each group), however this may not reflect clinical practice.

Overall, ticagrelor appears to be more effective in preventing ischaemic events, with a similar rate of major bleeding. However, clopidogrel should be preferred over ticagrelor in patients with:

- chronic dyspnoea

- increased risk of intracranial haemorrhage

- bradycardia or a history of ventricular pauses

- a risk of non-compliance due to the twice-daily dosing requirement of ticagrelor.

\section{Prevention of stent thrombosis}

In TRITON-TIMI-38, prasugrel was more effective in preventing stent thrombosis than clopidogrel (1.1\% vs $2.4 \%, p<0.001) .{ }^{1}$ A post hoc analysis of PLATO found that the rates of stent thrombosis were lower with ticagrelor than with clopidogrel over a period of up to 12 months ( $2.9 \%$ vs $3.8 \%$ ). ${ }^{19}$ Higher rates of stent thrombosis could be expected in patients who do not adhere to the twice-daily regimen of ticagrelor.

\section{Optimum duration and withdrawal of treatment}

Current Australian guidelines suggest that following acute coronary syndrome treated with any form of stenting, dual antiplatelet therapy, including aspirin, should be continued for 12 months. ${ }^{4}$ After 12 months, the risk of haemorrhage may outweigh potential cardiovascular benefits. Dual antiplatelet therapy may be prescribed for longer than 12 months in patients with drug-eluting stents.

In cases of acute coronary syndrome treated with coronary artery bypass grafting, the data are currently inadequate to make a recommendation for or against dual antiplatelet therapy after surgery.

Opinion is divided as to whether abrupt clopidogrel cessation results in a 'platelet rebound' effect causing thrombotic events. Studies have demonstrated mixed results. ${ }^{20-22}$ Clopidogrel tapering has been proposed as a strategy to minimise the risk, but the benefits of this are unclear. The decision to cease or taper antiplatelet therapy should be made at the discretion of the treating cardiologist. Aspirin should be continued indefinitely if tolerated. 


\section{Management of bleeding}

There are no formal guidelines for the management of bleeding related to $\mathrm{P}_{2} \mathrm{Y}_{12}$ inhibitors. The most common approach is platelet transfusion, but there are no clinical trials of its efficacy and the number of units required has not been standardised. There are no drugs to reverse the effect. The treating cardiologist should be contacted about the bleeding for advice on whether or not to stop the antiplatelet drug. Given the lack of data and standardised protocols on platelet transfusion, consultation with a haematologist may also be required.

\section{Perioperative management}

The antiplatelet drugs prescribed to prevent coronary occlusion also increase the risk of bleeding during surgery. Aspirin should be continued, with the exception of certain high-risk procedures such as neurosurgical, ophthalmological or prostate surgery, which cannot be delayed. ${ }^{23} \mathrm{P}_{2} \mathrm{Y}_{12}$ inhibitors are more difficult to manage.

\section{Elective major surgery}

Surgery produces a prothrombotic state where myocardial ischaemia may develop if the $\mathrm{P}_{2} \mathrm{Y}_{12}$ inhibitor has been ceased, even if aspirin is continued. Current guidelines recommend delaying elective surgery until after the 12-month course of dual antiplatelet therapy is complete. ${ }^{4}$

In some cases, $\mathrm{P} 2 \mathrm{Y}_{12}$ inhibitors may be temporarily withheld one month after bare metal stenting or six months after insertion of a drug-eluting stent at the discretion of the treating cardiologist. This period of time correlates to complete re-endothelialisation of the stents in animal models.

While it is generally accepted that clopidogrel should be ceased five days before elective surgery, the timing of discontinuation of prasugrel and ticagrelor is uncertain. There are no randomised trials to guide management, so recommendations have been based on pharmacokinetic data. If appropriate, prasugrel should be ceased seven days before elective surgery, and ticagrelor between 3 and 5 days, depending on the patient's thrombotic risk. ${ }^{23-25}$ In light of the lack of conclusive data, the treating cardiologist should be consulted about stopping $\mathrm{P}_{2} \mathrm{Y}_{12}$ inhibitors before elective surgery.

\section{Emergency surgery}

There are no formal guidelines for the management of patients on dual antiplatelet therapy who need emergency surgery. One strategy is perioperative platelet transfusion.

\section{Spinal or epidural anaesthesia}

The risk of epidural haematoma following neuraxial blockade is believed to be increased in patients taking dual antiplatelet therapy, although further studies are required. Precautions regarding antiplatelet therapy should be similar to those observed for surgery. In elective circumstances, $\mathrm{P}_{2} \mathrm{Y}_{12}$ inhibitors should be stopped before the procedure and in the case of an emergency lumbar puncture or neuraxial blockade, platelet transfusion is recommended beforehand to minimise the risk of severe haemorrhage. ${ }^{26}$

\section{Conclusion}

Ticagrelor and prasugrel have some advantages over clopidogrel in selected patients. Platelet inhibition is more rapid with prasugrel, and for both drugs the rates of ischaemic events and stent thrombosis are statistically lower. However, the risk of haemorrhage is higher than with clopidogrel.

Perioperative management of patients on dual antiplatelet therapy is a controversial area. The risks of myocardial ischaemia and haemorrhage need to be balanced judiciously for each individual patient. $\varangle$

Conflict of interest: none declared
SELF-TEST QUESTIONS

True or false?

1. Aspirin should not be used at the same time as prasugrel or ticagrelor.

2. Antiplatelet therapy is not required by patients with drugeluting stents.

Answers on page 219

\section{REFERENCES}

1. Wiviott SD, Braunwald E, McCabe CH, Montalescot G, Ruzyllo W, et al; TRITON-TIMI-38 Investigators. Prasugrel versus clopidogrel in patients with acute coronary syndromes. N Engl J Med 2007;357:2001-15

2. Roe MT, Armstrong PW, Fox KA, White HD, Prabhakaran D, et al; TRILOGY-ACS Investigators. Prasugrel versus clopidogrel for acute coronary syndromes without revascularization. N Engl J Med 2012;367:1297-309.

3. Wallentin L, Becker RC, Budaj A, Cannon CP, Emanuelsson $\mathrm{H}$, et al: PLATO Investigators. Ticagrelor versus clopidogrel in patients with acute coronary syndromes. N Engl J Med 2009;361:1045-57.

4. Chew DP, Aroney CN, Aylward PE, Kelly AM, White HD, Tideman PA, et al. 2011 Addendum to the National Heart Foundation of Australia/Cardiac Society of Australia and New Zealand Guidelines for the management of acute coronary syndromes (ACS) 2006. Heart Lung Circ 2011;20:487-502.

5. Damman P, Woudstra P, Kuijt WJ, de Winter RJ, James SK. P2Y12 platelet inhibition in clinical practice. J Thromb Thrombolysis 2012;33:143-53.

6. Wallentin L. P2Y12 inhibitors: differences in properties and mechanisms of action and potential consequences for clinical use. Eur Heart J 2009;30:1964-77.

7. McLachlan AJ, Campbell TJ. Variability in response to clopidogrel. Aust Prescr 2010;33:62-3.
8. Zhou D, Andersson TB, Grimm SW. In vitro evaluation of potential drugdrug interactions with ticagrelor: cytochrome $\mathrm{P} 450$ reaction phenotyping, inhibition, induction, and differential kinetics. Drug Metab Dispos 2011;39:703-10.

9. Teng R, Mitchell PD, Butler KA. Pharmacokinetic interaction studies of co-administration of ticagrelor and atorvastatin or simvastatin in healthy volunteers. Eur J Clin Pharmacol 2013;69:477-87.

10. Teng R, Butler K. A pharmacokinetic interaction study of ticagrelor and digoxin in healthy volunteers. Eur J Clin Pharmacol 2013;69:1801-8.

11. Teng R, Oliver S, Hayes MA, Butler K. Absorption, distribution, metabolism and excretion of ticagrelor in healthy subjects. Drug Metab Dispos 2010;38:1514-21

12. Gurbel PA, Bliden KP, Butler K, Tantry US, Gesheff T, Wei C, et al. Randomized double-blind assessment of the ONSET and OFFSET of the antiplatelet effects of ticagrelor versus clopidogrel in patients with stable coronary artery disease: the ONSET/OFFSET study. Circulation 2009;120:2577-85.

13. Hochholzer W, Trenk D, Frundi D, Blanke P, Fischer B, Andris K, et al. Time dependence of platelet inhibition after a 600-mg loading dose of clopidogrel in a large, unselected cohort of candidates for percutaneous coronary intervention. Circulation 2005:111:2560-4. 
14. Zhu B, Effron MB, Kulkarni MP, Li YG, Jakubowski JA, Miller DL, et al. The onset of inhibition of platelet aggregation with prasugrel compared with clopidogrel loading doses using gatekeeping analysis of integrated clinical pharmacology data. J Cardiovasc Pharmacol 2011;57:317-24.

15. Price MJ, Walder JS, Baker BA, Heiselman DE, Jakubowski JA, Logan DK, et al. Recovery of platelet function after discontinuation of prasugrel or clopidogrel maintenance dosing in aspirin-treated patients with stable coronary disease: the recovery trial. J Am Coll Cardiol 2012;59:2338-43.

16. Harrison P, Frelinger AL, Furman MI, Michelson AD. Measuring antiplatelet drug effects in the laboratory. Thromb Res 2007;120:323-36.

17. Wittfeldt A, Emanuelsson H, Brandrup-Wognsen G, van Giezen JJ, Jonasson J, Nylander S, et al. Ticagrelor enhances adenosine-induced coronary vasodilatory responses in humans. J Am Coll Cardiol 2013;61;723-7.

18. Storey RF, Becker RC, Harrington RA, Husted S, James SK, Cools F, et al. Characterization of dyspnoea in PLATO study patients treated with ticagrelor or clopidogrel and its association with clinical outcomes. Eur Heart J 2011;32:2945-53.

19. Steg PG, Harrington RA, Emanuelsson H, Katus HA, Mahaffey KW, Meier B, et al. Stent thrombosis with ticagrelor versus clopidogrel in patients with acute coronary syndromes: an analysis from the prospective, randomized PLATO trial. Circulation 2013;128:1055-65.
20. Djukanovic N, Todorovic Z, Grdinic A, Vojvodic D, Prostran M, Ostojic M, et al. Thienopyridine resistance among patients undergoing intracoronary stent implantation and treated with dual antiplatelet therapy: assessment of some modifying factors. J Pharmacol Sci 2008;107:451-5.

21. Yedidya I, Netzer A, Vaduganathan M, Solodky A, Kornwoski R, Lev El. Clopidogrel tapering as a strategy to attenuate platelet rebound phenomenon in patients with bare-metal stents. J Thromb Thrombolysis 2012;33:16-21.

22. Diehl P, Halscheid C, Olivier C, Helbing T, Bode C, Moser M. Discontinuation of long term clopidogrel therapy induces platelet rebound hyperaggregability between 2 and 6 weeks post cessation. Clin Res Cardiol 2011;100:765-71.

23. Cutlip D, Windecker S. Elective noncardiac surgery after percutaneous coronary intervention. UptoDate; 2014.

www.uptodate.com/contents/elective-noncardiac-surgery-afterpercutaneous-coronary-intervention [cited 2014 Nov 3]

24. Hillis LD, Smith PK, Anderson JL, Bittl JA, Bridges CR, Byrne JG, et al. 2011 ACCF/AHA guideline for coronary artery bypass graft surgery: a report of the American College of Cardiology Foundation/American Heart Association Task Force on practice guidelines. Circulation 2011;124:e652-e735.

25. Mohr TS, Brouse SD. Perioperative management of antiplatelet agents. Orthopedics 2012;35:687-91.

26. Howard-Alpe GM, de Bono J, Hudsmith L, Orr WP, Foex P, Sear JW. Coronary artery stents and non-cardiac surgery. Br J Anaesth 2007;98:560-74.

\section{Dental note}

\section{New antiplatelet drugs}

\section{Christopher G Daly}

Chair

Dental Therapeutics

Committee

Australian Dental

Association
Dentists should be familiar with clopidogrel, which is commonly used in combination with aspirin following placement of coronary stents to prevent coronary stent thrombosis. Clopidogrel may also be used in patients who are unable to take aspirin. Ticagrelor and prasugrel are new antiplatelet drugs that may be used as alternatives to clopidogrel.

All antiplatelet drugs place patients at an increased risk of bleeding following invasive dental procedures, especially dental extractions or dentoalveolar surgery. In patients who are receiving dual antiplatelet therapy following coronary artery stenting, premature discontinuation of the drugs can increase the risk of stent thrombosis, which may lead to acute myocardial infarction and death.

Australian guidelines ${ }^{2}$ recommend that patients requiring dental extractions or dentoalveolar surgery should not cease antiplatelet therapy, either monotherapy with aspirin, or dual therapy where aspirin is combined with other antiplatelet drugs. Patients should be warned of the increased risk of prolonged bleeding and also bruising.
Local measures such as placement of haemostatic materials into sockets and suturing should be used. If patients stop these medicines without substitute anticoagulants or monitoring, there is a risk of significant cardiac events or cerebrovascular accident. Elective extractions or surgery are best delayed if possible, especially in patients taking dual antiplatelet therapy temporarily (usually 12 months following stent placement).

It is important that a thorough medical history, including a medication history, is obtained for all patients. This should be updated at each visit. For patients requiring dental extractions or dentoalveolar surgery, their antiplatelet medication should not be ceased. ${ }^{2}$ However, their treating physician should be made aware of the planned procedures. When a dentist lacks experience in the oral surgical management of patients on antiplatelet therapy, the patient should be referred to an oral and maxillofacial surgeon for specialist management.

\section{Conflict of interest: none declared}

\section{REFERENCES}

1. Grines CL, Bonow RO, Casey DE Jr, Gardner TJ, Lockhart PB, Moliterno DJ, et al. Prevention of premature discontinuation of dual antiplatelet therapy in patients with coronary artery stents: a science advisory from the American Heart Association, American College of Cardiology, Society for Cardiovascular Angiography and Interventions, American College of Surgeons, and American Dental Association, with representation from the American College of Physicians. Circulation 2007;115:813-8.

2. Oral and Dental Expert Group. Therapeutic guidelines: oral and dental. Version 2. Melbourne: Therapeutic Guidelines Limited; 2012. p. 138-40. 